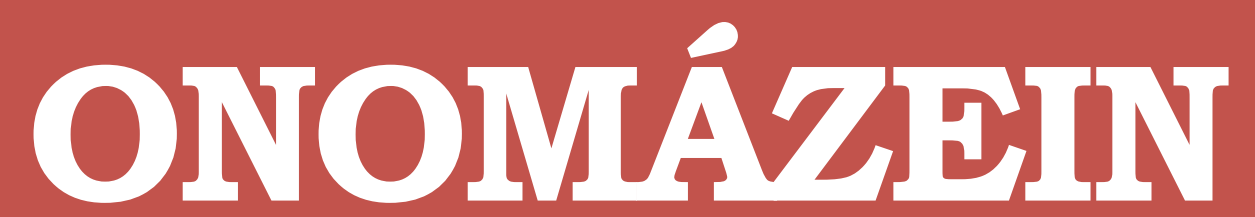

Revista de lingüística, filología y traducción
PONTIFICIA UNIVERSIDAD CATÓLICA DE CHILE FACULTAD DE LETRAS

\title{
Los textos necroturísticos: caracterización y desafíos para su traducción (francés-español)
}

Necrotourism texts: characterization and challenges for its translation (French-Spanish)

Francisco Luque Janodet

Universidad de Sevilla

Número especial

- VII -

Discurso

turistico,

lenguas y

traducción

2020
ONOMÁZEIN | Número especial VII - Discurso turístico, lenguas y traducción: 242-263

DOI: 10.7764/onomazein.ne7.08

ISSN: 0718-5758

\section{(c) $($ i $\fallingdotseq$}

Francisco Luque Janodet: Departamento de Filología Francesa, Universidad de Sevilla. ORCID: 0000-0001-56943233. | E-mail: fljanodet@us.es

Fecha de recepción: noviembre de 2019

Fecha de aceptación: abril de 2020 


\section{Resumen}

El necroturismo es un área poco estudiada desde la turismología y los estudios en lingüística, terminología y traductología. De hecho, el desconocimiento de este tipo de turismo se traduce en un número restringido de investigaciones, a menudo muy locales, y ha provocado que no se tengan datos o cifras a nivel nacional o regional. La presente contribución pretende complementar los estudios ya emprendidos en turismología, realizando para ello un análisis discursivo de los textos necroturísticos en francés y en español. Así pues, compilaremos un corpus textual en ambos idiomas, compuesto por guías turísticas, folletos y páginas webs. De esta manera, estudiaremos las características léxico-semánticas, morfosintácticas y pragmático-culturales de estos textos, con el fin, además, de facilitar su traducción. Nuestro estudio concluye que no existe un discurso necroturístico como tal, sino un discurso turístico particular, caracterizado por una gran interdisciplinariedad y por los numerosos campos semánticos que nutren su léxico, como la arquitectura y el arte. Hemos observado, además, que nos encontramos ante un discurso muy marcado por la cultura, ya que cada sociedad tiene una relación particular con la muerte y los lugares de inhumación.

Palabras clave: análisis del discurso; necroturismo; traducción; turismo.

\section{Abstract}

Necrotourism is a little-studied area from tourismology, linguistics, terminology and translatology. In fact, tourists' lack of knowledge about this type of tourism is reflected in a limited number of researches, often very locally conducted. It has also led to a lack of data or surveys at national or regional level. This paper aims to complement the studies already undertaken in tourismology, carrying out a discursive analysis of the necrotourist texts in French and Spanish. Therefore, a textual corpus in both languages, composed of tourist guides, brochures and websites will be compiled. In this way, we will study the lexical-semantic, morphosyntactic and pragmatic-cultural characteristics of these texts, in order to facilitate their translation. This preliminary research concludes that there is not a necrotourist discourse as such, but a particular tourist discourse, characterized by a great interdisciplinarity and by the numerous semantic fields that nourish its lexicon, such as architecture and history of art. It has been also observed that this discourse is very influenced by culture, since each society has a particular relationship with death and places of burial.

Keywords: discourse analysis; necrotourism; translation; tourism. 


\section{Introducción}

El sector turístico goza de gran relevancia a nivel internacional, con especial repercusión en los países europeos y americanos. En España — país en que, junto con Francia, se centrará el presente artículo-, la demanda turística supuso 147946 millones de euros en 2018, lo que se traduce en el 12,7\% del PIB anual (INE, 2019: 1). Asimismo, durante 2019, España recibió 83,7 millones de turistas internacionales, un 1,1\% más que el año anterior, según la Estadística de Movimientos Turísticos en la Frontera (2020). Por su parte, Francia recibió un total de 87 millones de turistas y el sector turístico representó el 7,4\% de su PIB en 2018, con unos ingresos por valor de 173000 millones de euros (Centre de documentation Économie Finances, 2019). Así pues, nos encontramos ante un sector en alza, pero, sobre todo, caracterizado por la amplitud y evolución de su oferta. El tradicional turismo de sol y playa ha dado paso a otros tipos de turismos como el turismo cultural, gastronómico, rural, etc. De esta manera, han surgido diferentes actividades que recurren, por ejemplo, al potencial agroalimentario 0 monumental de una región para potenciar la llegada de turistas nacionales e internacionales. Por estos motivos y habida cuenta de la necesidad de estudiar los segmentos que componen el sector turístico desde el ámbito de las humanidades, en la presente contribución abordaremos un tipo particular de turismo cultural: el necroturismo, mediante el cual se pone en valor la arquitectura y manifestaciones artísticas de los cementerios, a partir de la realización de visitas individuales, guiadas o teatralizadas. Por ello, realizaremos un estudio del sector necroturístico en el par de idiomas español y francés. Posteriormente, tras la compilación de un corpus textual, realizaremos un estudio de este discurso, prestando especial atención a los planos retórico, léxico-semántico y morfosintáctico. Este análisis se enfocará, finalmente, en una perspectiva traductológica que permita observar los posibles problemas de traducción que existan en este discurso.

\section{El necroturismo: estado de la cuestión}

El necroturismo ha comenzado a darse a conocer en España en los últimos años, si bien es cierto que se trata de un sector turístico con relativa tradición en Europa. Esta situación de desconocimiento generalizado justificaría la escasa producción científica generada en torno a este concepto, concentrada fundamentalmente en trabajos fin de grado y tesis doctorales en España y Latinoamérica (véase Pérez García, 2015; González Vela, 2016; Cano Avendaño, 2017; La Riva Vegazzo, 2017; Mantilla Aguirre, 2018, entre otros) y de distintas publicaciones en revistas científicas (Privitera, 2016; Rodríguez-Marín, 2018). Su relativa novedad ha dado lugar, además, a numerosas voces para denominar este concepto. Así, hemos documentado, tras la fase de revisión bibliográfica previa, las denominaciones necroturismo y turismo de cementerios (Sanmartín Sáez, 2019: 70); turismo negro (Rivero Sainz, 2017); en Perú, turismo funerario (Bocchio Pérez y Zanoni Cristell, 2017), y las variantes necro turismo (Guillén Herrera y Vera, 2016) y necro-turismo (González Vela, 2016). Esto nos demuestra la novedad de este objeto de 
estudio y su reciente inclusión en la literatura científica en turismología. No obstante, no hay estudios, a fecha de hoy, que aborden la naturaleza de estos textos y del discurso empleado en el ámbito necroturístico desde los postulados de la lingüística, la textología, la traductología o la terminología.

El necroturismo', neologismo compuesto por la raíz de origen griego nekrós ('muerto') y turismo, es definido por Rodríguez Marín (2018: 3) como "una parcela del turismo cultural centrada en la visita a estos espacios, que cada vez más aparecen relacionados entre los recursos turísticos en las guías impresas y webs de promoción turística”. Olmos Juárez y García Cebrían (2011: 105-106) prefieren definirlo como un tipo de turismo que

[...] consiste en visitas guiadas a cementerios y catacumbas. Normalmente se ofrece el servicio de un guía quien informa sobre las tumbas y los monumentos fúnebres. Este tipo de recorridos permite al turista conocer más de la cultura y costumbres del lugar que visita; por tanto, está orientado a aquellos turistas que buscan algo diferente en sus viajes, que valoran, desde el punto de vista visual, la belleza de las esculturas y de la vegetación propia de algunos cementerios y, desde el punto de vista cultural, la historia de personajes de todo tipo [...]. En cuanto a los destinos [...], son muy diversos, cualquier cementerio de cualquier destino turístico tiene algo que contar.

En consecuencia, nos encontramos ante una modalidad 1) perteneciente al turismo cultural; 2) en la que se visitan lugares relacionados con la muerte², como cementerios, mausoleos, catacumbas, criptas, etc., los cuales son entendidos como elementos propios de la cultura del lugar de destino, abarcando tanto las costumbres como la arquitectura, el arte y los personajes históricos y de relevancia social en la población.

En lo que respecta a las cifras de turistas y de visitas a monumentos necroturísticos, debemos señalar la escasa información disponible a día de hoy en los países objeto de estudio, algo que ya han puesto de manifiesto otros autores como Dancausa Millán (2019) y González Vela (2016: 15), quien señaló que "el necroturismo es un producto turístico en proceso de desarrollo, con escasa importancia para el mercado turístico y un déficit de investigación importante”. Así pues, no hay cifras oficiales concretas a nivel nacional que ilustren el estado del sector actual. Contamos, únicamente, con algunos estudios locales como el de González Vela (2016: 21), según el cual las visitas guiadas al cementerio de Torrero (Zaragoza, España) aumentaron de 1100 turistas en 2014 a 2000 en 2016; así como los de Dancausa Millán (2019: 211-212), quien

1 Preferimos la voz necroturismo, ya que, siguiendo las propuestas de la Fundación del Español Urgente (2011), los prefijos deben escribirse unidos a las palabras que acompañan salvo en determinadas excepciones que no se cumplen en este caso.

2 No hay que confundirlo con el turismo negro, tanaturismo, tanatoturismo, turismo oscuro o turismo del dolor, que engloba aquellos viajes o estancias asociados a las tragedias y a la muerte y que, por tanto, incluye castillos o campos de concentración (Olmo Juárez y García Cebrían, 2011: 108). 
afirma que el cementerio de Monturque (Córdoba, España) recibió un 20\% más de visitas en 2017 con respecto a 2016, con un total de 2300 turistas, cuyo lugar de procedencia era la propia localidad (13\%), la provincia de Córdoba (45\%), la Comunidad Autónoma de Andalucía (32\%), el resto de comunidades autónomas de España (8\%) y solo un 2\% de fuera de España. Esta autora (2019: 213-214) señala, además, que en la ciudad de Córdoba los turistas suelen provenir mayoritariamente de la Comunidad Autónoma de Andalucía (55,2\%) y solo un 0,4\% son turistas internacionales.

En Francia, el conocido como tourisme de cimetières o tourisme funeraire goza de más tradición que en el país ibérico3. Así pues, según los datos de la Office du Tourisme et des Congrès de Paris (2019), el cementerio de Père-Lachaise acoge a más de 3 millones de visitantes anualmente; pero, de nuevo, no encontramos estudios concretos centrados en este segmento turístico. Cabe señalar que, en Francia, destaca el tourisme de mémoire4 o tourisme mémoriel, definido por Cavaignac y Deperne (2003) como "une démarche incitant le public à explorer des éléments du patrimoine mis en valeur pour y puiser l'enrichissement civique et culturel que procure la référence au passé”. Este tipo de turismo, según Atout France (2012), tiene cuatro objetivos bien definidos: 1) dar testimonio de los sucesos del pasado; 2) explicar y poner en perspectiva estos sucesos; 3) contribuir a la reflexión de generaciones futuras; 4) favorecer el desarrollo económico de territorios sin otros atractivos turísticos. Por tanto, es un segmento del turismo centrado en los memoriales o lugares donde han ocurrido batallas o con un significado especial en uno de los conflictos bélicos en los que se ha visto inmersa Francia en el último siglo y medio (guerra franco-prusiana, Primera Guerra Mundial, Segunda Guerra Mundial). Crahay (2014: 151) distingue varios tipos de turistas de memoria: 1) las personas con una relación personal con el lugar, siendo víctimas o descendientes de víctimas o de actores del suceso; 2) los visitantes motivados por un motivo científico o pedagógico; 3 ) las personas que

3 De acuerdo con Lassère (1997: 603), el movimiento romántico ha sido posiblemente el punto de partida del necroturismo, ya que inspiraba una visión bucólica de los recintos de inhumación, que los convertía en un lugar de reposo tanto para vivos como para los fallecidos. De acuerdo con este autor (1997: 605), el ideal de cementerio romántico se materializa en Francia con la apertura del cementerio de Père-Lachaise en mayo de 1804. Según Sánchez García (2019: 1), este mismo antecedente puede hallarse en España con las muestras de culto dedicadas a las figuras insignes británicas y a sus lugares de enterramiento desarrolladas desde la segunda mitad del siglo XVIII. Así pues, los británicos desde comienzos del siglo XIX tomaron la costumbre de visitar las tumbas de compatriotas enterrados en cementerios europeos, como es el caso de la tumba del general John Moore en A Coruña (Sánchez García, 2019: 1).

4 Véase al respecto el informe Les assises du tourisme de mémoire del Secrétariat Général pour l'Administration de Francia. Recuperado de <https://www.defense.gouv.fr/content/download/ 125760/1235192/file/DP\%20_Assises\%20tourisme\%20de\%20m\%C3\%Agmoire.pdf> [fecha de consulta: 01 de abril de 2020].

5 "un enfoque que alienta al público a explorar elementos del patrimonio mejorado para aprovechar el enriquecimiento cívico y cultural proporcionado por la referencia al pasado". 
visitan un memorial como atracción turística o cultural. De hecho, tal es el éxito de este tipo de turismo en Francia que el turismo de memoria atrae a 20 millones de visitantes anuales, de los cuales, aproximadamente, la mitad son extranjeros (Direction Générale des Entreprises, 2018). Asimismo, según Cavaignac y Deperne (2003), esto ha motivado el desarrollo de "Chemins de mémoire", una iniciativa del Ministère des Armées y de la Direction des Patrimoines, de la Mémoire et des Archives, que propone itinerarios temáticos en Francia, organizados en torno a la fortificación (siglos XVI-XX), la guerra franco-prusiana (1870-1871), la Primera Guerra Mundial (1914-1918) y la Segunda Guerra Mundial (1939-1945).

\section{La traducción turística, traducción especializada}

Antes de abordar la naturaleza del discurso de los textos necroturísticos, nos parece necesario fundamentar nuestro estudio a partir de investigaciones precedentes enmarcadas en el ámbito turístico en general. De acuerdo con Alcaraz Varó y otros (2000, citado en Mira Rueda, 2009: 30), los campos semánticos relacionados con el sector turístico son el alojamiento, la cultura, el clima, el arte, el derecho, los deportes, la gestión, los juegos, el paisaje, el marketing, los seguros, el viaje y la restauración. En lo que respecta al léxico, Alcaraz Varó y otros (2000, citado en Mira Rueda, 2009: 41) proponen cuatro grandes sectores en los que categorizar el vocabulario de la industria del turismo: 1) viajes y seguros; 2) alojamiento; 3) gastronomía, y 4) recreo e industria del ocio.

Estos sectores, de acuerdo con Calvi (2016: 191-192), tienen en común la organización empresarial, la cual se divide en dos apartados: 1) gestión a nivel macroeconómico (agencias gubernamentales) y a nivel microeconómico (agencias de hoteles, por ejemplo) y 2) el marketing, ya que abarca la venta de productos turísticos y su promoción.

Teniendo esto en cuenta, Calvi (ibid., 192-193) considera tres grandes caudales léxicos en el discurso turístico:

1) El núcleo de términos específicos, relacionados con las estructuras turísticas y los servicios. Según esta autora (ibid.), estos términos expresan saberes propios de los gestores turísticos, como la terminología empleada en la clasificación de los hoteles. En este núcleo se encuentran unidades terminológicas creadas mediante mecanismos internos como la composición y la derivación, así como la adopción de extranjerismos y los términos acuñados para hablar del fenómeno turístico.

2) Unidades terminológicas de disciplinas y actividades relacionadas con la descripción de la oferta turística y la práctica del turismo, como la historia del arte o la artesanía. Como señala Calvi (2016: 193), estos términos "no están resemantizados dentro de los textos turísticos, pero tienden a asumir valores pragmáticos diferentes de los originarios, dependiendo del género textual en el que estén insertos". 
3) Vocablos del léxico general que responden a un intento de persuasión, a la implicación de valores, etc.

Por ello, Calvi (2016: 193-194) distingue entre 1) el léxico del turismo, creado por los estudiosos para enfocar y describir el turismo y empleado en su comunicación habitual, y 2) el léxico de los textos turísticos. En este sentido, como señala Zaro Vera (2005: 12), una de las características especiales de los textos turísticos es la unión de información y persuasión y de objetividad y publicidad en función de los estilos discursivos de cada cultura y lengua.

Calvi (2010: 22-23) también recoge los principales géneros textuales del sector turístico, que presentamos brevemente:

- géneros editoriales; elaborados en el mundo editorial, responden a una demanda de información por parte del turista, como la guía y las revistas de viajes;

- géneros institucionales, emanados de organismos institucionales con el propósito de posicionar o de afianzar la imagen de un destino turístico, como los folletos, anuncios, páginas webs, etc.;

- géneros comerciales, como anuncios, catálogos de viajes, folletos de hoteles; son desarrollados por los departamentos de marketing de las agencias y de empresas turísticas;

- géneros organizativos, como los billetes, las reservas, las cartas, facturas o contratos entre las agencias y distintos sectores como la hostelería, los transportes, las ferias;

- géneros legales, como las normativas y los reglamentos; pertenecen al campo del derecho y son empleados para reglamentar o legislar determinados aspectos del sector;

- géneros científicos y académicos que estudian el turismo;

- géneros informales como foros y blogs de viajeros.

No obstante, como señala Calvi (2010: 23), estas figuras no son excluyentes, sino abiertas. Asimismo, esta autora (ibid.) considera la existencia de una serie de macrogéneros textuales caracterizados por la hibridación de diferentes géneros, estilos o tipologías textuales, entre los que se encuentran la guía de turismo, el folleto, la revista de viajes y turismo, el catálogo de viajes y las páginas webs.

Por tanto, la amplitud del sector turístico no se manifiesta únicamente en la variedad de temáticas abordadas en el plano léxico, sino también en los distintos géneros, macrogéneros y subgéneros a los que ha dado lugar y que condicionarán las producciones escritas de los emisores y los actos comunicativos formales de acuerdo con factores como la situacionalidad y las características del emisor y del receptor.

6 Véanse al respecto los estudios de Durán Muñoz (2011: 65). 


\section{Metodología}

La realización de estudios de análisis del discurso exige la compilación de un corpus textual. La primera fase exigible en este tipo de investigaciones es el establecimiento de unos criterios de diseño sólidos que evite posibles interferencias en la fase de análisis del corpus. Por ello, tomaremos como referencia los estudios de Seghiri Domínguez (2006: 217 y ss.), a partir de los cuales podemos afirmar que: 1) según el porcentaje y distribución de los textos incluidos en el corpus, hemos compilado un corpus comparable bilingüe (francés-español); hemos tratado que sea un corpus equilibrado en cuanto a número de textos en cada par de idiomas; 2) según la especificidad de los textos, hemos compilado un corpus especializado, ya que pretende mostrar un uso particular de la lengua, en este caso, el discurso necroturístico en francés y español; 3) según la selección del texto, se trata de un corpus textual, ya que hemos escogido textos completos; 4) de acuerdo con el nivel de anotación, nos encontramos ante un corpus anotado, ya que hemos indicado la fecha de compilación y la URL.

Seguidamente, hemos seguido la metodología protocolizada de Seghiri Domínguez (2011), formada por cuatro etapas: 1) búsqueda y acceso a la documentación; 2) descarga de datos; 3) normalización; 4) almacenamiento. El análisis cuantitativo del corpus ha sido realizado usando el programa informático AntConc (2019), desarrollado por Lawrence Anthony. El análisis discursivo propuesto toma como referencia los estudios de Pascual Cabrerizo (2016), quien ha abordado la naturaleza del texto enoturístico, caracterizado - al igual que el texto necroturístico- por su hibridación.

\section{El necroturismo: textos, discurso y problemas de traducción}

Los textos necroturísticos son una tipología de textos turísticos caracterizada, principalmente, por la temática, donde se hace un uso particular del discurso turístico. Se trata, como hemos visto, de una actividad que goza de tradición en Europa y que empieza a generar interés en España, lo cual ha dado lugar a actividades como las jornadas culturales y gastronómicas Mundamortis, organizadas por el ayuntamiento de Monturque (Córdoba); los 9 días ad eternum, organizados por el Cementerio Sacramental de San Isidro de Madrid, y el Concurso de Cementerios de España. Antes de proceder al análisis de nuestro objeto de estudio, presentaremos los datos cuantitativos de nuestro corpus de trabajo:

\begin{tabular}{llll} 
CORPUS TEXTUAL & ESPAÑOL & FRANCÉS & TOTAL \\
N. ${ }^{\circ}$ de textos & 39 & 24 & 63 \\
\hline Word types & 5738 & 4470 & 10208 \\
\hline Word tokens & 27653 & 19720 & 47373 \\
\hline
\end{tabular}


Como se puede observar, pese a haber un desequilibrio de 15 textos entre el corpus español y francés, los resultados cuantitativos de word tokens y word types son muy similares, lo cual nos Ileva a afirmar que los documentos franceses contienen una mayor cantidad de palabras y lemas que han podido ser analizados porAntConc. Dichos documentos abordan, concretamente:

En español:

El cementerio de Arenys de Mar; el cementerio de Barcelona; el cementerio de Bilbao; el cementerio de Ciriego; el cementerio de la Almudena; el cementerio de Lloret de Mar; el cementerio de Monturque (Córdoba); el cementerio de Nuestra Señora de la Fuensanta (Córdoba); el cementerio de Nuestra Señora de la Salud (Córdoba); el cementerio de Poblenou; el cementerio de Polloe; el cementerio de Reus (Tarragona); el cementerio de Sabadell (Barcelona); el cementerio de Terassa (Barcelona); el cementerio de Torrero; el cementerio de Vilafranca; el cementerio de Villaluenga del Rosario (Cádiz); el cementerio dels Caputxins de Mataró; el Cementerio Histórico Artístico de San Miguel (Málaga); el cementerio inglés de Málaga; el cementerio Jardín de Alcalá de Henares; el cementerio monumental e histórico de Granada; el cementerio municipal de León; finalmente, un folleto del Festival Mundamortis.

\section{En francés:}

Le cimetière de l'Est (Rennes); le cimetière de la Chartreuse (Bordeaux); le cimetière de la Croix-Rousse; le cimetière de Loyasse (Lyon); le cimetière de Montparnasse; le cimetière de Saint Paul de Vence; le cimetière de Saint Pierre d'Aix-en-Provence; le cimetière de Saint Tropez; le cimetière du Père-Lachaise; le cimetière protestant de Montpellier.

Todos estos documentos, como señala Pascual Cabrerizo (2016), se enmarcan en la categoría de textos promocionales e informativos orientados al turista y se pueden dividir específicamente en folletos y páginas webs de instituciones públicas y privadas. Tomaremos como referencia, en este caso, Ios estudios de Calvi (2010: 23), quien considera los folletos y las páginas webs como un macrogénero textual, caracterizados por una hibridación de diferentes tipologías textuales y estilos, entre otros.

Aunque el objetivo fundamental de este estudio no es realizar un análisis traductológico contrastivo entre un texto origen y un texto meta, hemos constatado un cierto interés por ofrecer la oferta necroturística en distintos idiomas a partir de la traducción de las páginas webs, folletos y guías.

Así pues, en la oferta proveniente de España, encontramos una institución que ofrece sus servicios en español, catalán, francés e inglés; otra institución cuya oferta está en español, inglés y francés; otra, en inglés y español; otro organismo, en español y francés, y, finalmente, otra empresa en español y catalán. El resto de las páginas webs se oferta únicamente en español. 
En francés, una página web, de donde hemos compilado tres textos, se ofrece en francés, alemán, inglés, italiano, coreano, chino, japonés, español, portugués, neerlandés y ruso. Otra página web ofrece sus textos en francés, inglés y español. Las páginas webs restantes lo hacen únicamente en francés.

Consideradas estas cuestiones, abordaremos las principales características de los folletos y guías necroturísticas y, posteriormente, de los contenidos publicados en HTML, ya que, como hemos señalado previamente, estos documentos constituyen dos macrogéneros textuales diferenciados.

\subsection{Folletos y guías necroturísticas}

\subsubsection{Características a nivel extratextual}

Como señala Pascual Cabrerizo (2016: 283), los folletos se suelen caracterizar por las funciones informativa y persuasiva, algo que también ocurre en los folletos y guías necroturísticos. Así pues, encontramos una función persuasiva mediante recursos como los siguientes:

- En francés, se hace una interpelación directa al lector mediante el pronombre personal vous (3 repeticiones). Para conseguir la implicación del lector, se ha empleado el pronombre nous (4 repeticiones) y los determinantes posesivos notre (2 repeticiones) y nos (2 repeticiones).

- En español, se ha empleado el plural sociativo mediante el uso de los determinantes posesivos nuestro (4 repeticiones), nuestros (2 repeticiones), nuestra (4 repeticiones, una vez descontadas las repeticiones del sintagma "Nuestra Señora de", ya que forma parte del nombre de algunos cementerios), nuestras (1 repetición) y el pronombre nos (4 repeticiones). Así pues, las formas verbales más frecuentes se encuentran en tercera persona del singular y primera persona del plural: encontramos (1 repetición) y podemos (2 repeticiones). Como se puede observar, la finalidad de la primera persona del plural es la creación de un vínculo más cercano con el lector.

Como señala Pascual Cabrerizo (2016: 286), una marca lingüística de la función persuasiva es la fuerte adjetivación presente en los folletos, algo que se manifiesta en los dos idiomas de nuestro corpus:

Obélisque monumental, le plus élevé du cimetière $(9 \mathrm{~m})$ ?

7 Recuperado de <https://www.lyon.fr/sites/lyonfr/files/content/migrated/149/203/cimetiere_loyasse1-0.pdf> [fecha de consulta: 02 de abril de 2020]. 
Grand bourgeois et illustre personnage de l'histoire maçonnique .

Pyramide monumentale en pierre qui est une reproduction du monument maintenant détruit, construit aux Brotteaux en mémoire des victimes de la Terreur ${ }^{9}$.

[...] el gran valor cultural y arquitectónico del cementerio de "Nuestra Señora de la Salud"”.

[...] este bello monumento funerario para el Panteón de la familia [... $]^{11}$.

\subsubsection{Factores microtextuales}

La morfosintaxis en los folletos franceses y españoles se caracteriza por el uso de yuxtaposiciones y el empleo de oraciones sin verbo, dado el marcado carácter visual de estos documentos. Así pues, los folletos, que suelen estar compuestos por dos páginas, dedican la primera de ellas a la presentación del plano y a la leyenda para interpretarlo, con los nombres de los lugares de interés. La segunda página, por regla general, presenta el cementerio si esto no se ha realizado anteriormente, y en ella se incluyen unas notas biográficas de los personajes célebres enterrados en el cementerio. Estas notas suelen ser breves, de no más de 100 palabras de extensión, y se caracterizan por la nominalización. Por tanto, el número de formas verbales es muy limitado, pero podemos destacar el uso del pasado simple y del presente con valor histórico en ambos idiomas. Asimismo, hemos encontrado un uso más bien restringido de imperativo en francés (n’oubliez pas; découvrez la beauté; décryptez les messages), pero ningún caso en español.

\subsubsection{Contenido y estructura}

Los folletos analizados se caracterizan por tener, en su mayoría, una estructura homogénea. Así pues, la mayoría poseen:

1) un lema o eslogan;

2) una introducción histórica del cementerio en cuestión;

3) presentación de los lugares de interés histórico-artístico;

4) en algunos folletos, presentación de los lugares de interés paisajístico;

8 Recuperado de $<$ https://www.lyon.fr/sites/lyonfr/files/content/migrated/22/81/cimetiere_loyasse2.pdf> [fecha de consulta: 02 de abril de 2020].

9 Recuperado de <https://www.lyon.fr/sites/lyonfr/files/content/migrated/149/203/cimetiere_loyasse1-0.pdf> [fecha de consulta: 02 de abril de 2020].

10 Recuperado de <https://www.turismodecordoba.org/repositorio/2019/2019073014484100000015 64490921.0887.pdf?cache=1564490921.198> [fecha de consulta: 02 de abril de 2020].

11 Recuperado de <https://www.turismodecordoba.org/repositorio/2019/2019073014484100000015 64490921.0887.pdf?cache=1564490921.198> [fecha de consulta: 02 de abril de 2020]. 
5) en francés, los cinco folletos analizados presentan planos, mientras que en español, únicamente aparece en la mitad de los folletos;

6) en casos muy reducidos, se ha incluido un glosario con los latinismos más empleados y su significado en lengua meta;

6) información práctica para el usuario (horario de apertura, teléfono, dirección, página web);

7) información y menciones legales: edición, referencias bibliográficas, copyright de las imágenes.

En lo que respecta al contenido, este se encuentra generalmente bien distribuido en el documento. Los folletos necroturísticos se caracterizan por su brevedad y un mayor énfasis de la función apelativa. Por su parte, las guías necroturísticas presentan una información más detallada dada su mayor extensión. Así pues, suelen incluir información relativa a la visita, a las instalaciones y partes del cementerio, información de tipo botánico para la descripción del paisaje y notas biográficas sobre las personas célebres enterradas en el cementerio.

Los folletos se centran, sobre todo, en la presentación del plano del cementerio donde se encuentran las efemérides enterradas, propuestas de rutas y una breve biografía de dichas personas. Dichos documentos suelen venir acompañados de un eslogan, como Histoires de vies, mémoire de la ville (cementerio de Rennes), La mémoire d'un quartier (cementerio de la CroixRousse, Lyon), Des pierres qui parlent (cementerio de Loyasse, Lyon), La ciudad de los recuerdos (Córdoba). En todos los folletos y guías hemos podido encontrar el logotipo de la institución que los ha creado y solo en uno hemos encontrado más símbolos. Hablamos de la guía del Cimetière de la Chartreuse de Burdeos, donde aparecen los logotipos de la UNESCO, de Patrimonio de la Humanidad, del Ayuntamiento de Burdeos y de Archives Bordeaux Métropole. Por otro lado, solo en un documento de los cuatro analizados se incluye un código QR, que redirige al lector a una página web donde se presentan dos mapas, uno del Cimetière de l'Est y otro del Cimetière du Nord de Burdeos. Si el lector pulsa en uno de los mapas, se ofrece una visita virtual en $360^{\circ}$ del recinto con sonido ambiental, información del cementerio y de las personalidades enterradas.

En lo que respecta al paratexto, además de los planos, se ha optado en los cuatro documentos por una tipografía clara y de color negro sobre un fondo blanco. El folleto del Cimetière de Rennes emplea un color verde oliva, mientras que los otros tres textos recurren al azul (uno de ellos a una imagen de un cielo con nubes blancas). En lo que respecta a las imágenes, encontramos fotografías de las tumbas y mausoleos, imágenes de insectos como mariposas, flores y árboles que pueblan el cementerio, caminos y calles del cementerio y monumentos.

\subsection{Páginas webs necroturísticas}

\subsubsection{Características a nivel extratextual}

En francés, se hace una interpelación directa al lector mediante el pronombre personal vous (32 repeticiones). El pronombre nous se ha empleado en 26 ocasiones. Asimismo, cons- 
tatamos el uso los determinantes posesivos notre (3 repeticiones), nos (7 repeticiones) y votre (12 repeticiones).

En español, se ha empleado el plural sociativo mediante el uso de los determinantes posesivos nuestro (10 repeticiones), nuestros (3 repeticiones), nuestra (8 repeticiones, una vez descontadas las repeticiones del sintagma "Nuestra Señora de"), nuestras (2 repeticiones) y el pronombre nos (28 repeticiones). De nuevo, la función persuasiva queda manifestada por la fuerte adjetivación existente en el corpus:

Le cimetière du Père-Lachaise appelé aussi « cimetière de l'Est », est le plus grand cimetière parisien ${ }^{12}$.

La visite commence avec l'incontournable couple de Saint-Germain- des-Prés, Jean-Paul Sartre et Simone de Beauvoir ${ }^{13}$.

On ressort de cette paisible promenade d'un pas reposé et sûrement pas la mort dans l'âme ${ }^{14}$.

Las tres dan a conocer la gran fuerza simbólica del camposanto y lo abren a la ciudadanía con una perspectiva diferente ${ }^{15}$.

Un hermoso eje central enchinado bordeado de majestuosos árboles (cipreses, palmitos, boj, mirtos, rosales, péndulas, palmeras y verbenas), dan paso a ambos lados a panteones de marcado interés arquitectónico e histórico ${ }^{16}$.

Una visita inolvidable en un espacio hasta ahora desconocido. Un viaje acompañados de arte, historia, bellos paisajes, divertidísimas anécdotas, y ¿por qué no?, descubrir un nuevo espacio en la ciudad para reflexionar sobre el sentido lúdico de la vida ${ }^{17}$.

\subsubsection{Factores microtextuales}

Las páginas webs presentan, por regla general, una sintaxis más rica y compleja en ambos idiomas.

12 Recuperado de <https://pere-lachaise.com/> [fecha de consulta: 02 de abril de 2020].

13 Recuperado de <https://paris-capitale-historique.fr/visite/le-cimetiere-montparnasse/> [fecha de consulta: 02 de abril de 2020].

14 Recuperado de <https://www.bordeaux-quartiers.fr/visite-du-cimetiere-de-la-chartreuse-vous-neresterez-pas-de-marbre/> [fecha de consulta: 02 de abril de 2020].

15 Recuperado de 〈http://redaragon.elperiodicodearagon.com/turismo/que_hacer/default. asp?accion=pagina\&cosaquehacer_id=2623> [fecha de consulta: 02 de abril de 2020].

16 Recuperado de <https://cementeriosvivos.es/cementerios/cementerio-de-nuestra-senora-de-lasalud-cordoba/> [fecha de consulta: 02 de abril de 2020].

17 Recuperado de <http://granadaatraves.com/rutas/paseo-guiado-al-cementerio-monumental-ehistorico-de-granada/> [fecha de consulta: 02 de abril de 2020]. 
En francés predominan las oraciones simples con la estructura sujeto, verbo y objeto, pero también oraciones complejas mediante subordinación. Se ha empleado mayoritariamente la tercera persona del singular y del plural para describir el cementerio y los servicios funerarios que ofrece, así como la vida de las personas inhumadas en ellos. La primera persona del plural ha sido empleada, por parte de las empresas o instituciones emisoras, para referirse a sí mismas. No obstante, en estos documentos, se ha empleado, mayoritariamente, la tercera persona del singular, especialmente para hablar de las características del cementerio o de un personaje ilustre, y la primera y segunda persona del plural (vous como fórmula de cortesía). Asimismo, cabe señalar el importante uso del pronombre on (47 repeticiones). En este caso, como ha señalado Yao (2018: 79), on suele poseer dos funciones: una función incluyente, mediante la cual es equivalente a nous, y un valor excluyente, por la que representa a vous (informal y formal), tu, il, elle, ils y elles. Asimismo, según este autor (ibid.), su uso puede corresponderse con una oración impersonal con el pronombre se en español. Este último empleo ha sido el más recurrente en los textos.

En lo que respecta a los tiempos verbales en los documentos francófonos, encontramos el empleo mayoritario del passé composé, en más de 40 ocasiones, pero también hemos documentado un acusado uso del passé simple, empleado generalmente en discursos más formales y literarios, en alternancia con el imperfecto. Hemos encontrado un uso muy limitado del imperativo en francés (découvrez les nombreux secrets; cherchez; ne vous laissez pas). En lo que respecta a la voz, existe un equilibrio en el uso de la voz activa y pasiva. Asimismo, destaca el uso de formas pronominales con sentido pasivo (on se décide à créer; le tombes blanches se dessinent), así como oraciones pasivas impersonales (il est décidé que). Hallamos, además, otras construcciones impersonales como il s'agit (3 repeticiones), il y a (2 repeticiones), il faut (6 repeticiones) y las construcciones del tipo à + infinitivo (à lire aussi).

En español, se ha documentado un uso continuado de la segunda persona del plural (vosotros) para referirse al turista. Asimismo, este matiz de informalidad se intensifica mediante el uso de la segunda persona del singular (tú), posiblemente para crear una relación más estrecha con el receptor. El uso de usted se encuentra mucho más restringido que en francés.

En lo que respecta a los tiempos verbales empleados, constatamos en ambos idiomas la alternancia de los tiempos de pasado. Así pues, hemos detectado el uso del presente de indicativo (con valor de presente y valor histórico), del imperfecto (planteaba, llamaba, consideraba) y del pretérito perfecto simple (encargó, realizó, autorizó, diseñó). Asimismo, hemos hallado seis casos de pretérito pluscuamperfecto. No hemos documentado el uso de imperativo en español, aunque esta forma de exhortación se manifiesta mediante otros recursos como las construcciones impersonales del tipo poder + infinitivo (13 repeticiones), deber + infinitivo (2 repeticiones), así como soler + infinitivo (2 repeticiones). En lo que respecta al uso de la voz, destacamos el empleo acusado de la voz activa. No obstante, también señalamos el uso de oraciones impersonales como es necesario, se tiene constancia, se produce, se pueden adquirir flores, se narra, pronto se dirá. 
Por otro lado, la caracterización de las páginas webs necroturísticas varía enormemente en función de la naturaleza del emisor. Únicamente dos de las páginas webs consultadas en francés y en español corresponden a empresas dedicadas al necroturismo. El resto de documentos ha sido descargado de otros sitios más amplios, generalmente, de páginas webs oficiales de turismo o, en el caso de municipios de población más reducida, de la página oficial de la localidad. Por regla general, los documentos y la distribución de las páginas webs de temática necroturística no difiere en gran medida de los folletos. Así pues, se realiza un acercamiento histórico al cementerio en cuestión, una exposición de los elementos de carácter social e histórico del cementerio y, finalmente, una presentación de los elementos artísticos y arquitectónicos del recinto. Concluye esta estructura con información útil al usuario como el horario de apertura, precio, galería de imágenes, hiperenlace a Google Street View y Google Maps, duración aproximada de las rutas, dirección, teléfono y correo electrónico de contacto, etc. De manera particular, algunas páginas webs incorporan información relativa a las instalaciones o al compromiso del cementerio en cuestiones sociales o medioambientales. En el caso de empresas, se incluyen hiperenlaces a los perfiles en redes sociales como Twitter, Instagram, Facebook y a plataformas audiovisuales como Youtube.

En lo que respecta a la presentación de estas páginas, normalmente se emplea una tipografía clara, de color negro para el cuerpo del texto y, para los títulos, rojo, negro y azul. En cuanto al paratexto, estas páginas webs presentan una gran cantidad de imágenes de los cementerios en cuestión: panorámicas de las tumbas o de los nichos, fotografías de ciertas tumbas -ya sea por su interés arquitectónico o por tratarse de tumbas de personas célebres-y, finalmente, imágenes de monumentos o edificios, como capillas, iglesias y panteones. Asimismo, dada la orientación de estos documentos a ofrecer una imagen de los cementerios como un lugar de interés paisajístico, se muestran imágenes de los espacios verdes, calles y lagunas de los recintos. Tanto en la parte final de los textos como en el cuerpo de texto encontramos planos del cementerio con leyendas que permiten localizar los monumentos y tumbas de interés al lector. Finalmente, es importante señalar el uso de logotipos, ya sean de los ayuntamientos e instituciones públicas o privadas que emiten el texto, como aquellos logotipos que pretenden facilitar que el lector encuentre información relevante rápidamente.

\subsection{El léxico en los textos necroturísticos}

Consideradas las cuestiones morfosintácticas y pragmáticas de los textos necroturísticos, abordaremos, finalmente, su léxico. El léxico es uno de los elementos más característicos de un discurso de especialidad, aunque coincidimos con Franco Aixelá (2015) al no considerarlo como el único rasgo definitorio. De hecho, en el ámbito técnico, Newmark (1988) afirma que la terminología especializada raramente supera el 10-20\% del léxico del texto. No obstante, esto no es óbice para considerar la importancia del léxico como rasgo característico de cualquier discurso de especialidad como el turístico. Para el análisis de este plano, hemos estudiado el 
conjunto de textos (guías, folletos y páginas webs), dado que todos se enmarcan en una misma temática y las posibles diferencias que pudiesen existir serán muy reducidas.

En español, constatamos los siguientes campos semánticos:

- Léxico de la administración y política, con ejemplos como Ayuntamiento, Bien Nacional, concesión administrativa, decreto, empresa, escritura pública, espacios en alquiler, expropiado, propiedad municipal, Real Cédula, registro de la propiedad, suelo en propiedad, zona de administración.

- Léxico de la arquitectura, como ala, ampliación, arquitectura de alto valor artístico, arquitectura gótica, arquitectura modernista, arquitectura neoclásica, arquitectura popular andaluza, arquitectura románica, bóveda de cañón rectangular, bóveda de crucero, bovedillas, cisternas romanas, cornisamento de apoyo, intervenciones arquitectónicas, muro, nave de dos tramos, patrimonio arquitectónico, planta de cruz griega, pechinas, portalada neoclásica, torre. Dentro de este campo semántico, encontramos distintas divisiones, como el de la arquitectura religiosa (capilla, convento, iglesia, monasterio) y el léxico de la arquitectura de los lugares de inhumación.

- Léxico de la botánica: acacias, adelfas, árbol de Júpiter, árboles de hoja perenne, árboles de sombra de hoja ancha, árboles de sombra, árboles frutales, boj, catalpas, cinamomos, ciprés, Jacaranda mimosaefolia, jacarandas, lantanas, mirtos, olmos, palmeras palmitos, parterre, patrimonio vegetal, péndulas, rosales, siempreverdes, verbenas.

- Léxico de la fauna: aves, animales, especies, mamíferos.

- Léxico de la geografía: campiña, enclave paisajístico, orografía, Sierra Nevada, topografía, vega de Granada.

- Léxico del arte y la historia del arte: arte funerario, aspecto armónico, calidad artística, conjunto plástico, escultor, estética ecléctica, estética funeraria, fachada neoclásica, fachada simétrica, modernista, mosaico, neoclásico, neogótico, obra de arte, recinto neoclásico.

- Léxico de la historiografía y la historia: centuria decimonónica, Guerra Civil, guerra de la independencia, franquismo, histórico, Liberalismo, Los Sitios, postguerra, reinado de Fernando VII, rigor histórico, Romanticismo.

- Léxico de la medicina: epidemia, fiebre amarilla.

- Léxico de los cementerios y su arquitectura: calle, camposanto, columbarios, crematorio, esculturas funerarias, funerario, inhumación, mausoleo, necrópolis, nichos, oratorio, osarios, panteón, sala de ceremonias, sala de vela, sepultura, servicio fúnebre.

- Léxico religioso: altar, Caputxins, crucifijo, frailes, hornacina, Junta de Obra de Santa María, martirio, multiconfesional, Orden de los Capuchinos, púlpito, triunfo. 
- Léxico turístico: a demanda, ASCE (Asociación de Cementerios Significativos Europeos), centro de interpretación, cita previa, descuentos, entrada, grupos, museo al aire libre, paseo al aire libre, paseo guiado, programa cultural, punto de información, Ruta Europea de Cementerios, ruta, viaje, visita dramatizada, visita guiada, visita teatralizada.

En francés, hemos hallado los siguientes campos semánticos:

- Léxico de la administración y política: bénéficiaire, concession temporaire, décret impérial, maire, ordonnance royale, tsar Nicolas II, ville.

- Léxico de la arquitectura: architecture symétrique, chapelle néo-classique, caveau haussmannien, colonnes tronquées, dalles gigognes en granit, fronton triangulaire, y, concretamente, léxico de la arquitectura religiosa: basilique du Sacré-Cœur, cathédrale, chapelles, églises.

- Léxico de la botánica: arborée, arbustes, chênes, ensemble verdoyant, érables, fleurs asiatiques, marronniers, tilleuls, thuyas.

- Léxico de la geografía: colline, colline de Fouvière, sol accidenté, terrain.

- Léxico de la historia del arte: Académique Baroque, éclectique, empire gothique, haussmannien, monumental, neo-baroque, neo-byzantin, neo-classique, Second empire, style Napoléon III.

- Léxico de la historiografía y la historia: Anciens combattants, Ancien Régime, guerre de 1870, Première guerre mondiale, Seconde Guerre mondiale, soldats de la garnison de Rennes.

- Léxico de la medicina: problèmes sanitaires.

- Léxico de la religión: bouddhiste, catholique, cérémonies, coutumes pratiqués, ecclésiastiques, musulman, office religieux, protestant, rites, Toussaint.

- Léxico de los cementerios y su arquitectura: allées, architecture funéraire, bureau d'accueil du public, catacombes, columbarium, crémation, emplacement cinéraire, épitaphes, inhumation, monument du Souvenir Français, nécropole, ossuaire, salle de recueillement, sépulture, stèle blanche, tombe gothique.

- Léxico de los medios de transporte: funiculaire, stations, FOL (chemins de fer Fourvière et de l'Ouest Lyonnais), OTL (Omnibus et Tramway de Lyon), tramway.

- Léxico de nuevas tecnologías: connectique, micro, supports numériques.

- Léxico del turismo: activité insolite, guide, guide accrédité, guide officiel, guider, prestataires indépendants, touriste, visite guidée, voyageur.

Asimismo, hemos hallado un importante número de figuras retóricas en ambos idiomas, especialmente metáforas y metonimias. Muchas de las metáforas documentadas poseen una 
naturaleza antropomórfica, ya que entienden el dominio fuente en términos de los seres humanos, como, por ejemplo, árboles serios, rigurosos ${ }^{18}$; espacio con personalidad propia ${ }^{19}$; un museo [...] que relata 200 años de historia20. En francés encontramos el mismo fenómeno, manifestado en expresiones como atmosphère incite au recueillement ${ }^{21}$; dans l'enceinte du cimetière règne un silence o les tombes racontent des vies ${ }^{22}$.

Otras metáforas están relacionadas con objetos valiosos (joyas arquitectónicas ${ }^{23}$ ), mientras que, en otros, la historia y la vida se entienden en términos de un lugar o un edificio (dar un paseo por la vida de la ciudad ${ }^{24}$ ). Además de estas figuras retóricas, hemos constatado el empleo de metáforas creativas como [las personas enterradas] son historia viva²5.

Cabe señalar, además, la presencia de distintos elementos que podrían ser problemáticos en este plano, como la existencia juegos de palabras (vous ne resterez pas de marbre ${ }^{26}$ ) y, especialmente, los problemas de índole cultural o culturemas, dada la relación tan estrecha entre muerte, cementerios y cultura. Entre ellos, destacamos diferentes variaciones intralingüísticas, como ficelle, utilizada en Lyon para denominar a los funiculares; así como ciertas expresiones del tipo Roque Mignon, proveniente de grimpe mon mignon, la cual, según el texto turístico en el que aparece, era gritada por los curiosos a quienes se dirigían a la horca para ser ejecutados ${ }^{27}$.

18 Recuperado de 〈https://cecosam.cordoba.es/es/el-cementerio/vegetacion-paisajeg> [fecha de consulta: 02 de abril de 2020].

19 Recuperado de<https://cementeriosvivos.es/cementerios/cementerio-de-terrassa/> [fecha de consulta: 02 de abril de 2020].

20 Recuperado de <https://cementeriosvivos.es/visita-el-cementerio-dels-caputxins-de-mataro-a-tuaire-un-museo-al-aire-libre-que-relata-200-anos-de-la-historia-arte-y-arquitectura-de-la-ciudad/> [fecha de consulta: 02 de abril de 2020].

21 Recuperado de <http://rennes-cim.alkante.com//accueil/infos_pratiques/espace_documentaire/41_49/plaquette_cimetiere_de_lest/> [fecha de consulta: 02 de abril de 2020].

22 Recuperado de <http://rennes-cim.alkante.com//accueil/infos_pratiques/espace_documentaire/41_49/plaquette_cimetiere_de_lest/> [fecha de consulta: 02 de abril de 2020].

23 Recuperado de <https://cementeriosvivos.es/cementerios/cementerio-de-nuestra-senora-de-lasalud-cordoba/> [fecha de consulta: 02 de abril de 2020].

24 Recuperado de <http://granadaatraves.com/rutas/paseo-guiado-al-cementerio-monumental-ehistorico-de-granada/> [fecha de consulta: 02 de abril de 2020].

25 Recuperado de <https://cementeriosvivos.es/cementerios/cementerio-municipal-de-leon/> [fecha de consulta: 02 de abril de 2020].

26 Recuperado de <https://www.bordeaux-quartiers.fr/visite-du-cimetiere-de-la-chartreuse-vous-neresterez-pas-de-marbre/> [fecha de consulta: 02 de abril de 2020].

27 Información recuperada de <http://rennes-cim.alkante.com//accueil/infos_pratiques/espace_documentaire/41_49/plaquette_cimetiere_de_lest> [fecha de consulta: 02 de abril de 2020]. 


\section{Conclusiones}

A la luz de lo expuesto, consideramos que es poco apropiado hablar de un discurso necroturístico como tal, debido a la gran cantidad de características morfosintácticas, pragmáticas y léxico-semánticas que comparten con los textos turísticos centrados en otras temáticas. Es cierto que el léxico y la temática son factores fundamentales, aunque no determinantes, para poder considerar un discurso como una lengua o sublengua de especialidad. No obstante, hemos podido observar en esta investigación que no existe un léxico necroturístico propiamente dicho, sino más bien una gran cantidad de campos semánticos y de discursos de especialidad que confluyen para poder articular un texto de esta temática. Hemos podido observar que la arquitectura es una de las principales fuentes de las que beben estos textos, así como el arte, la historia del arte y la botánica. Una de las características de estos textos es su gran interdisciplinariedad, más que la presencia de un léxico concreto, determinado y limitado. No podemos pasar por alto que nos encontramos ante un tipo de actividad híbrida, donde confluyen los servicios funerarios y el turismo.

Si bien es cierto que estos documentos presentan prácticamente los mismos campos semánticos, las palabras y términos que los conforman pueden diferir en gran medida en una y otra lengua, particularmente en los dominios de la arquitectura y la historia, puesto que cada región ha tenido su evolución propia. A estas diferencias conceptuales debemos añadir el uso de metáforas, conceptuales en muchos casos, poéticas y creativas en otros, en el par de idiomas estudiado. La presencia de culturemas y elementos culturales también queda patente ante la estrecha relación que tienen los cementerios, la muerte y la cultura.

Hemos presentado, pues, un estudio preliminar que ha abordado, de manera general, las principales características de los textos necroturísticos y en el que se ha incidido en el alto grado de interdisciplinariedad que ellos presentan. Estos elementos representan una serie de retos que el traductor turístico deberá enfrentar y abordar en su proceso de trasvase interlingüístico y de mediación intercultural, siendo esta última especialmente relevante dado que la concepción de la muerte depende enormemente de la cultura en cuestión y, según el caso, puede ser un elemento comúnmente aceptado o un tabú. Se puede concluir que la traducción de textos necroturísticos es una línea de investigación novedosa y muy poco abordada desde los distintos ámbitos y disciplinas de las humanidades.

\section{Bibliografía citada}

Alcaraz Varó, Enrique, Brian Hugues, Miguel Ángel Campos Pardillos y Víctor Manuel Pina Medina, 2000 : Diccionario de términos de turismo y de ocio. Inglés-Español, Spanish-English, Barcelona, Ariel.

Anthony, Lawrence, AntConc [software informático], Tokio: Waseda University [https://www. laurenceanthony.net/software, fecha de consulta: 02 de abril de 2020]. 
Atout France, 2012: Le tourisme de mémoire en France [http://www.atout-france.fr/content/ tourisme-de-memoire, fecha de consulta: 02 de abril de 2020].

Bocchio Pérez, Daniella Patricia, y Franccesca Zanoni Cristell, 2017: Turismo funerario: caso cementerio de Miraflores, parte antigua. Tesis, Universidad Privada del Norte.

Calvi, Maria Vittoria, 2000: “El léxico del turismo". Universidad de Bérgamo [https://www.academia.edu/460042/El_L\%C3\%Agxico_Del_Turismo, fecha de consulta: 13 de abril de 2020].

Calvi, Maria Vittoria, 2010: "Los géneros discursivos en la lengua del turismo: una propuesta de clasificación”, Ibérica 19, 9-31.

Calvi, Maria Vittoria, 2016: "Léxico de especialidad y lengua del turismo" en Aura Luz Duffé Montalván (ed.): Estudios sobre el léxico. Puntos y contrapuntos, Frankfurt am Main: Peter Lang, 187-214.

Cano Avendaño, Juan Carlos, 2017: Tendencias turísticas para preservar el patrimonio histórico y artístico del cementerio de la ciudad de Riobamba. Trabajo de grado previo a la obtención del Título de Ingeniero, Universidad Nacional de Chimborazo en Riobamba.

Cavaignac, François, y Hervé Deperne, 2003: “Les chemins de mémoire. Une initiative de l'État”, Cahier Espaces 80, 12-21.

Centre de documentation Économie Finances, 2019: "Où trouver des informations statistiques officielles sur le tourisme?” [https://www.economie.gouv.fr/cedef/statistiques-officielles-tourisme, fecha de consulta: 25 de abril de 2020].

CRAHAY, Frédéric, 2014: “Tourisme mémoriel”, Témoigner. Entre histoire et mémoire 117, 151-152.

Dancausa Millán, María Genoveva, 2019: Análisis del Turismo Oscuro en Córdoba (España) - Pátzcuaro (México): El Turismo de Cementerios. Tesis doctoral, Universidad de Córdoba.

Direction Generale des Entreprises, 2018: Le tourisme de mémoire en France : un levier d'attractivité des territoires. Poids, enjeux et perspectives... [https://www.entreprises.gouv. fr/tourisme/tourisme-memoire-france-levier-d-attractivite-des-territoires, fecha de consulta: 25 de abril de 2020].

DURÁn Muñoz, Isabel, 2011: El trabajo ontoterminográfico aplicado a la traducción de textos del turismo de aventura (español-inglés-alemán): fases de preparación, elaboración y edición. Tesis doctoral, Universidad de Málaga.

Franco AixelÁ, Javier, 2015: “La traducción de textos científicos y técnicos”, Tonos Digital 29, 1-31. 
Fundación del Español URgente, 2011: "Prefijos: cuatro claves para una buena redacción" [https:// www.fundeu.es/recomendacion/prefijos-cuatro-claves-para-una-buena-redaccion-817/, fecha de consulta: 23 de abril de 2020].

GonzÁlez Vela, Verónica, 2016: El turismo de cementerios o necro-turismo. Trabajo Fin de Grado, Universidad de Zaragoza.

Guillén Herrera, Samuel Ricardo, y Víctor Vera, 2016: "Mitos, leyendas y tradiciones en el Cementerio Patrimonial Junta de Beneficencia de la ciudad de Guayaquil", Revista Cambios y Permanencias 7, 590-605.

Instituto Nacional de Estadistica, 2019: "Cuenta Satélite del Turismo de España (CSTE). Revisión estadística 2019. Serie 2016-2018. El peso del turismo alcanzó los 147.946 millones de euros en 2018, lo que supuso el 12,3\% del PIB" [https://www.ine.es/prensa/cst_2018.pdf, fecha de consulta: 03 de abril de 2020].

Instituto Nacional de Estadística, 2020: "Estadística de Movimientos Turísticos en Fronteras (FRONTUR). Diciembre 2019 y año 2019. Datos provisionales España recibe 4,3 millones de turistas internacionales en diciembre, un 0,9\% menos que en el mismo mes de 2018" [https://www.ine. es/daco/daco42/frontur/frontur1219.pdf, fecha de consulta: 02 de abril de 2020].

La Riva Vegazzo, Iván Felipe, 2017: Características de la parte antigua del cementerio de Miraflores como recurso turístico potencial para el necroturismo en la ciudad de Trujillo. Tesis para optar el grado de maestro, Universidad Nacional de Trujillo.

LASSERE Madeleine, 1997: “Le XIXe siècle et l'invention du tourisme funéraire”, Revue d'histoire moderne et contemporaine 4 (44), 601-616.

Mantilla Aguirre, Miguel Ángel, 2018: Atributos que posee el cementerio general de Miraflores - Distrito de Trujillo para el desarrollo del necroturismo. Tesis para optar el título profesional de licenciado, Universidad Nacional de Trujillo.

Mira Rueda, Concepción, 2009: El discurso turístico en inglés y en español. Su tratamiento lexicográfico, Sevilla: Consejería de Turismo, Comercio y Deporte. Junta de Andalucía.

Newmark, Peter, 1988: A Textbook of Translation, New York: Prentice Hall.

Office du Tourisme et des Congres de Paris, s. f.: "Balade insolite dans le cimetière du Père-Lachaise" [https://www.parisinfo.com/decouvrir-paris/balades-a-paris/balade-insolite-cimetiere-perelachaise, fecha de consulta: 13 de abril de 2020].

Olmos Juárez, Luisa, y Rafael García Cebrían, 2011: Estructura del Mercado Turístico, Madrid: Ediciones Paraninfo S.A. 
Pascual Cabrerizo, María, 2016: El texto enoturístico. Tesis doctoral, Universidad de Valladolid.

Pérez García, Luisa Victoria, 2015: Los cementerios de la provincia de Cádiz. Arte, Sociología y Antropología. Tesis doctoral, Universidad de Málaga.

Privitera, Donatella, 2016: "Cimiteri e Turismo. Potenzialità e Valorizzazione di un fenomeno in crescita”, In_bo: Ricerche e progetti per il territorio, la città e l'architettura 7 (10), 265-273.

Rivero SaInz, Santiago, 2017: Patrimonio y turismo negro en Cantabria: identificación y puesta en valor. Trabajo académico, Universidad de Cantabria.

Rodriguez-Marin, Francisco José, 2018: Factores exógenos y experiencias de gestión determinantes del éxito de cementerios europeos como producto turístico, XIX Encuentro Iberoamericano de Valoración y Gestión de Cementerios patrimoniales, 1-22 [https://hdl.handle. net/10630/17079, fecha de consulta:25 de abril de 2020].

Sánchez GarcíA, Jesús Ángel, 2019: "Antecedentes para el necroturismo en España. Visitantes británicos en la tumba del general John Moore en A Coruña (siglos XIX y XX)" en Francisco José Rodriguez Marín (ed.): Actas del XX Encuentro de cementerios patrimoniales. Los cementerios como recurso cultural, educativo y turístico, Málaga: Vicerrectorado de Investigación y Transferencia de la Universidad de Málaga, 1-19.

Sanmartín Saez, Julia, 2019: "Análisis del discurso, ideología y neologismos: turismofobia, turistización y turistificación en el punto de mira”, CLAC 78, 63-90.

Secretariat General pour l'Administration, 2011: Les assises du tourisme de mémoire. Dossier de prensa [https://www.defense.gouv.fr/content/download/125760/1235192/file/DP\%20_Assises\%20tourisme\%20de\%20m\%C3\%Agmoire.pdf, fecha de consulta: 23 de abril de 2020].

Seghiri Domínguez, Miriam, 2006: Compilación de un corpus trilingüe de seguros turísticos (español-inglés-italiano): aspectos de evaluación, catalogación, diseño y representatividad. Tesis doctoral, Universidad de Málaga.

Seghiri Domínguez, Miriam, 2011: "Metodología protocolizada de compilación de un corpus de seguros de viajes: aspectos de diseño y representatividad”, RLA: Revista de Lingüística Teórica y Aplicada 49 (2), 13-30.

YAO, Koffi, 2018: Gramática contrastiva español-francés. Para profesores y alumnos: niveles B1 y B2, París: L'Harmattan.

Zaro Vera, Juan Jesús, 2005: "Prólogo” en Adrián Fuentes Luque (ed.): La traducción en el sector turístico, Granada: Atrio, 11-13. 